Pikas E., Koskela L., and Seppänen O. (2017). "Design Management in a Design Office: Development of the Model 'To-Be'" In: LC3 2017 Volume II - Proceedings of the 25th Annual Conference of the International Group for Lean Construction (IGLC), Walsh, K., Sacks, R., Brilakis, I. (eds.), Heraklion, Greece, pp. 555-562. DOI: https://doi.org/10.24928/2017/0317

\title{
DESIGN MANAGEMENT IN A DESIGN OFFICE: DEVELOPMENT OF THE MODEL FOR 'TO-BE'
}

\author{
Ergo Pikas ${ }^{1}$, Lauri Koskela ${ }^{2}$, Olli Seppänen ${ }^{3}$
}

\begin{abstract}
As the third paper on design management in a series of three, design science research activity was carried out. Based on the problems identified within the first paper and the knowledge base established in the second paper, theoretical and practical design process and management models were developed. Within the language of two-step abductive reasoning, the theoretical model served as a solution concept for developing a practical solution. This research reports the first cycle of design science research. The result is the description of "to-be" to facilitate the change management within the case study organization.
\end{abstract}

Keywords: Root causes, design model, design management

\section{INTRODUCTION}

Within the first paper, problems were addressed and the conclusion was drawn that the design management of the case company is focused on the transformation view (Koskela et al., 2014). Essentially, this means that the company's interpretation of design task is too simplistic. In the second paper, we addressed the literature from the perspective of productive science (techne) to develop the theoretical knowledge base. Thus, the problems, the nature of the case study design organization and the knowledge base served this work as requirements and the source for developing a generic and practical new process and design management models. However, we must note that this work reports the first cycle of design science research. In the following, the method is described, the problems to be solved are outlined and the theoretical as well as the practical models are developed.

\section{METHOD}

Within this research, the design science research methodology is used (Figure 1). Within this last paper, in the series of three, first, a new theory based design process and management model ("to be") for systematically managing three complementary dimensions in a case study organization is developed. As the last step, the main author designed together with the members of the design office a new high level and second level process models. This became the basis for change management, which is a process too. Also the new models provide a framework or container for incorporating several methodologies, methods and tools to be used for better design management. The development of the design office design production and management model was carried out using the following steps: Forming an organizational product-process quality

1 Aalto University, Department of Civil Engineering, ergo.pikas@aalto.fi and Tallinn University of Technology, Faculty of Civil Engineering, ergo.pikas@ttu.ee

2 University of Huddersfield, School of Art, Design and Architecture

3 Aalto University, Department of Civil Engineering 
management team, including board members (two), heads of functional departments (altogether three, one from architecture, structure and building services each), project manager (one) and senior architects/engineers (one architect and one engineer). As the first step, every member of the team developed their own view of the design process and his/her sketches with the rest of the change management team. After that the first meeting was held to discuss different views on the design process and to develop an organization wide design process model on a high level. The latter was carried out based on the two conceptualizations of design proposed in the second article. Subsequently, three value stream mapping events for devising a new second level process model was carried out. Every meeting concluded with the discussion on the lessons learnt. Several weeks after the design science research sessions, semi-structured interviews with quality management team were conducted to evaluate the effects of the proposed models.

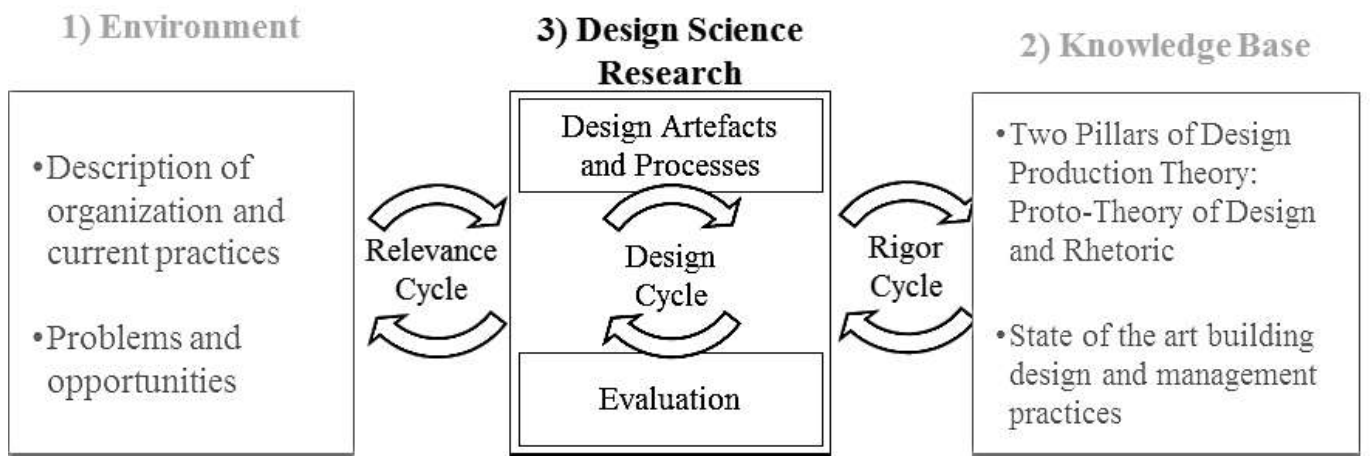

Figure 1. Design science research methodology for developing the future design process and management model (adapted from Hevner (2007)).

\section{DESIGN SCIENCE RESEARCH}

\subsection{Problems, Requirements and Countermeasures}

First, a summary of problems to be addressed within this work is outlined. Within this process, we had to take into account the needs of the company because DSR is always contextual. For example, the development of a company-wide process model required analyzing the sales process; i.e. the time period before the design contract. Analyzing sales was important because of the commitments made to the customer. Secondly, the company does not have all the building design services in-house, which means we had to explicitly include the sub-contractors into the process description as well. In Table 1, problems discussed and analyzed within the first paper are outlined with respective root causes. Additionally, we have proposed a list of countermeasures (means) based on the second article and other practices relevant to solve the problems. The idea is that the process model would become the container for the proposed means.

\subsection{Theoretical Solution Concept for Process Model Development}

Based on the proto-theory of design as well as design rhetoric and inspired by the "Vee" model (Forsberg et al., 2005) from systems engineering, first a theoretical high level process model was developed (shown in Figure 2). This includes two time periods (discovery and embodiment/construction) and two stages (planning/programming and concept design in discovery; design embodiment and production planning in embodiment/construction) within both periods. Within each stage the focus is on the 
particular aspect/domain of the artefact (Andreasen et al., 2015): activity - analysis of the use functions and properties (objectives, criteria and programming); organ - strategic selection of systems and sub-systems for design conceptualization; parts - design embodiment, an instantiation and materialization of selected concept(s), typically from schematic design through construction documentation; and process - design of the production system. With the exception of process domain, these could be considered also as environment, function/purpose and structure in Simon's (1981) analytical design science model.

Table 1. Summary of problems, root causes and possible countermeasures.

\begin{tabular}{|c|c|c|}
\hline Problems & Root Causes & Possible Countermeasures \\
\hline $\begin{array}{l}\text { Design management is concerned } \\
\text { with task and resource management }\end{array}$ & $\begin{array}{l}\text { Oversimplified conceptualization } \\
\text { of design task }\end{array}$ & $\begin{array}{l}\text { Proto-theory of design and design rhetoric } \\
\text { for explaining the design process and } \\
\text { thinking }\end{array}$ \\
\hline $\begin{array}{l}\text { Focus is on producing drawings } \\
\text { and models }\end{array}$ & $\begin{array}{l}\text { Assumption that the customer and } \\
\text { users know what they need and } \\
\text { want }\end{array}$ & \multirow{2}{*}{$\begin{array}{l}\text { Design rhetoric, design briefing, quality } \\
\text { function deployment, level of development } \\
\text { and customer/user involvement }\end{array}$} \\
\hline \multirow{2}{*}{$\begin{array}{l}\text { Late changes and patching (creative } \\
\text { workarounds) as the wrong thing } \\
\text { was done or the thing was done } \\
\text { wrong (errors) }\end{array}$} & $\begin{array}{l}\text { Poor and unsystematic } \\
\text { specification of customer/user } \\
\text { needs and requirements }\end{array}$ & \\
\hline & $\begin{array}{l}\text { No systematic investigation of } \\
\text { design alternatives }\end{array}$ & $\begin{array}{lcr}\text { Morphological charts, } & \text { Choosing-by- } \\
\text { Advantages, } & \text { Building } \text { Information } \\
\text { Modelling and A3-s for reporting and } \\
\text { documentation }\end{array}$ \\
\hline $\begin{array}{l}\text { Unaligned work scope, uncertainty } \\
\text { of information flows, poorly } \\
\text { coordinated work and assumption- } \\
\text { driven designs }\end{array}$ & Poor design process management & $\begin{array}{l}\text { Last Planner System, design structure } \\
\text { matrix, dialogue matrix and the rolling } \\
\text { wave concept }\end{array}$ \\
\hline $\begin{array}{l}\text { Unpredictable and unreliable plans, } \\
\text { resulting in unpredictable projects }\end{array}$ & $\begin{array}{l}\text { Design production control as } \\
\text { thermostatic model (planned } \\
\text { versus actual) }\end{array}$ & $\begin{array}{l}\text { Pull planning and make ready process on } \\
\text { phase, lookahead, weekly and daily } \\
\text { (huddle meetings) levels, design process } \\
\text { metrics and Plan-Do-Check-Act cycle and } \\
\text { A3-s for reporting and documentation }\end{array}$ \\
\hline Poor solutions and/or design errors & Poor design quality management & $\begin{array}{l}\text { Unit control/testing, checklists; BIM based } \\
\text { design coordination for integration and } \\
\text { coordination; prototypes, simulations, } \\
\text { design of experiments, Taguchi methods } \\
\text { and life-cycle optimization for } \\
\text { verification; and customer design reviews } \\
\text { and briefing for validation; A3 for } \\
\text { problem-solving }\end{array}$ \\
\hline
\end{tabular}

Rhetorical design assumes constructing partial wholes, either building physical or digital models to be tested on the different audiences (e.g. users or potential users, but also contractors, maintainers and public representatives). Thus, each stage has the two directions of the proto-theory of design, analysis and synthesis, or the two stages of rhetoric, invention and delivery.

Additionally, in a rhetorical discourse, every stage should start with studying and analyzing customers, their intentions, needs and values to be translated into requirements, typically including functional (e.g. number and areas' of spaces, indoor climate control) and non-functional requirements (e.g. facility must meet nearly Zero Energy Certification requirement). Every stage should finish with the customer/user value judgment (indicated with the diamond symbols in Figure 2). For the latter, customer design reviews and/or briefing sessions should be used. Using building information modelling and its functionalities allows the intermediate virtual construction of artefacts to facilitate the evaluation process by the relevant audiences (Eastman et al., 2011). 


\begin{tabular}{|l|c|c|c|c|}
\hline Time Periods & \multicolumn{3}{|c|}{ Discovery } & \multicolumn{2}{c|}{ Design Embodiment and Construction } \\
\hline $\begin{array}{l}\text { Stages } \\
\text { Product Ontology } \\
\text { Focus }\end{array}$ & $\begin{array}{c}\text { Planning and Programming } \\
\text { (Environment) }\end{array}$ & $\begin{array}{c}\text { Concept Design } \\
\text { Organ Domain } \\
\text { (Function) }\end{array}$ & $\begin{array}{c}\text { Pesign Embodiment } \\
\text { (Structure) }\end{array}$ & $\begin{array}{c}\text { Process Domain (Production } \\
\text { System Design) }\end{array}$ \\
\hline $\begin{array}{l}\text { Project Production } \\
\text { System Model }\end{array}$ &
\end{tabular}

Figure 2. Design project delivery model based on the interpretation of proto-theory of design and rhetoric in design.

In Figure 3, the content of each "Vee" model with steps, reasoning modes and types of activities of design are represented. Rhetoric is concerned with the 'outer' (users, goals, resources etc.) and proto-theory with the 'inner' (function, behavior and structure) environment.

In the left leg of the "Vee" model (analysis), design rhetoric requires designers to study the situation, users and their needs, to invent requirements, issues and ideas. This is the transformation from 'outer' to 'inner' environment, into the functional and nonfunctional requirements. In following, the first step in two-step abductive reasoning is the requirements loop, which is the movement from requirements to concept, and design loop is a movement from concept to design solution. This process is not a linear (from step to step) and mono-directional process, but can and typically includes iterations within designers' heads. For example, it has been studied that expert designers tend to propose a solution straightaway and then try to show that it fulfils all the requirements. On the other hand, novice designers try to derive a solution proceeding logically from what is required to meet the ends (Ahmed et al., 2003). These have also been described as solution and problem-oriented strategies (Wynn, 2007).

The right leg, the opposite direction to analysis, of the model is synthesis, which is about working towards the proof and demonstration. The two types of reasoning, deduction and composition, and two types of activities, assembly and testing, are used to move the design forward (shown in Figure 3). Within synthesis, the design information created in analysis is communicated to be implemented into/in a medium (e.g. calculations, drawings, specifications, BIM models), and later composed into partial or final wholes (e.g. BIM models) to be verified for example through tests, reviews and/or simulations (Fujimoto, 2007). As a last step in synthesis, the design solution is delivered to the customer/user for validation (Buchanan, 2007). Validation is the evaluation against customer and end user needs and expectations (desirability and usability). Thus, this process is ideally symmetrical, for every step in analysis there is a counter-activity in synthesis. Within each step of the design synthesis, the design output is verified against the counter step in analysis. 


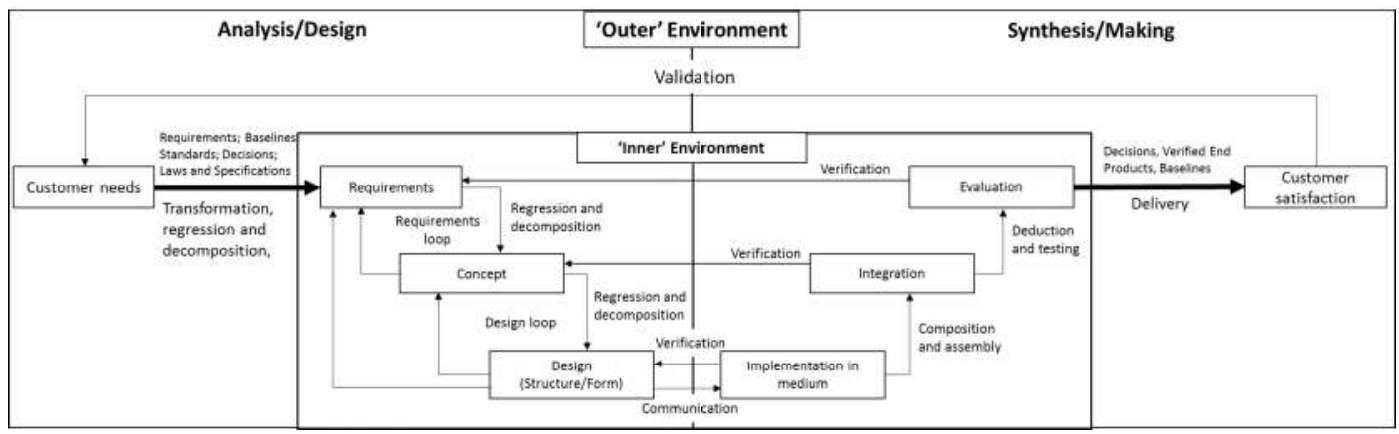

Figure 3. Design synthesis process with reasoning modes (partially adapted from Kapurch (2010)).

In Table 2 we are juxtaposing the design cognitive and process steps illustrated in Figure 3 with different methodologies, methods and tools to illustrate how and when the different methods and tools could be used. As the last step we have added the layer of design process management. This essentially means that design inquiry is almost always a collective activity. Thus, we have included collaborative methods such as the Last Planner System (Hamzeh et al., 2009), design structure matrix (Huovila et al., 1997) and some other process management related applications.

Table 2. Juxtaposition of the design cognitive and process steps with contemporary applications.

\begin{tabular}{|c|c|c|}
\hline Step & Explanation & Methodologies, Methods and Tools \\
\hline Transformation & $\begin{array}{l}\text { Transformation of customer needs, } \\
\text { requirements and baselines to } \\
\text { functional and non-functional } \\
\text { requirements }\end{array}$ & $\begin{array}{l}\text { Design briefing, quality function deployment, } \\
\text { level of development and customer/user } \\
\text { involvement }\end{array}$ \\
\hline $\begin{array}{l}\text { Requirements } \\
\text { (regression } \\
\text { decomposition) }\end{array}$ & \multirow{2}{*}{$\begin{array}{l}\text { From solution concept to design } \\
\text { solution, a second step in abductive } \\
\text { reasoning }\end{array}$} & \multirow{2}{*}{$\begin{array}{l}\text { Morphological charts, Choosing-by- } \\
\text { Advantages, Sketches and/or A3-s for } \\
\text { documentation }\end{array}$} \\
\hline $\begin{array}{l}\text { Design loop (regression } \\
\text { and decomposition) }\end{array}$ & & \\
\hline $\begin{array}{l}\text { Transmission to medium } \\
\text { and verification }\end{array}$ & $\begin{array}{l}\text { From design regression } \begin{array}{r}\text { and } \\
\text { decomposition to }\end{array} \text { tosign } \\
\text { implementation in medium }\end{array}$ & $\begin{array}{l}\text { Building Information Modelling, drawings, } \\
\text { specifications, calculations etc. and work unit } \\
\text { control testing, checklists and client reviews for } \\
\text { verification }\end{array}$ \\
\hline $\begin{array}{l}\text { Composition, assembly } \\
\text { and verification }\end{array}$ & From units of work to integrated whole & $\begin{array}{l}\text { Building Information Modelling, drawings, } \\
\text { specifications, calculations etc. and work unit } \\
\text { control/testing, checklists and BIM based } \\
\text { coordination and client reviews for verification }\end{array}$ \\
\hline $\begin{array}{l}\text { Deduction, testing and } \\
\text { verification }\end{array}$ & $\begin{array}{l}\text { From partial and final wholes to the } \\
\text { evaluation of design solution }\end{array}$ & $\begin{array}{l}\text { Building Information Modelling, A3 } \\
\text { documentation, prototypes, simulations, design } \\
\text { of experiments, Taguchi methods and life-cycle } \\
\text { optimization for verification }\end{array}$ \\
\hline Delivery & $\begin{array}{l}\text { From evaluation of artefact functioning } \\
\text { and behavior to the judgment of } \\
\text { objective worth }\end{array}$ & $\begin{array}{l}\text { Customer design reviews and briefing for } \\
\text { validation }\end{array}$ \\
\hline $\begin{array}{l}\text { Overall } \\
\text { Management }\end{array}$ & $\begin{array}{l}\text { All the design cognitive but as well as } \\
\text { process steps, which are the tasks types } \\
\text { should be managed from the collective } \\
\text { perspective as almost any design is } \\
\text { carried out by several complementary } \\
\text { disciplines }\end{array}$ & $\begin{array}{l}\text { Last Planner System, design structure matrix, } \\
\text { dialogue matrix, the rolling wave concept, pull } \\
\text { planning and make ready process on phase, } \\
\text { lookahead, weekly and daily (huddle meetings) } \\
\text { levels, design process metrics and Plan-Do- } \\
\text { Check-Act cycle }\end{array}$ \\
\hline
\end{tabular}

\subsection{Design Cycle for Developing Case Study Organization Process and Design Management Model}

Within this stage, the researcher together with the members (CEO, owner, heads of the departments and project manager) of the design office, designed first the high level 
process model and then the second level process model. The high level process model shown in Figure 4 was developed based on Figure 2. In this work we have excluded the stages related to sales. Besides the milestones and the division of the design embodiment stage into four phases, other aspects have been already described in section 3.2.

Milestones represent the larger deliverables, which essentially form a baseline for subsequent stages and phases. At every milestone, which is the start and the end of a design stage and phase, there is a meeting with a focus on understanding the customer priorities, needs and requirements and/or evaluating the outputs of respective stage or phase. These could be considered design briefings and/or client review meetings, proposed to have a standardized structure (objectives, participants, typical agenda and expected outputs). The aim of the standardized meetings is to facilitate teams focusing on the content rather than on the process - thus applying the principles of rhetoric, including the situation analysis, common ground and intention selection.

The first milestone is the signing of the contract. The second milestone requires the delivery of project requirements and program, including the description of project objectives - aspirations about quality, project outcomes, sustainability, budget, feasibility, site conditions and other parameters or constraints to develop the project initial brief and criteria for measuring project success (Sinclair, 2013, Ballard, 2000). At the second milestone, a project start-up meeting should be held for all the relevant stakeholders to create a common ground about the design task. The purpose of the start-up meeting is to answer two questions: what are our objectives and how are we going to work together throughout the entire project lifetime? The next milestone is the delivery of a general concept, typically including decisions about the selection of systems and solution strategies. At the meeting the proposed concepts will be assessed by the customer and other designers. We do not go into the details of the other milestones as these are typical to most project delivery models.

\begin{tabular}{|c|c|c|c|c|c|c|c|c|}
\hline Time Period & & \multicolumn{6}{|c|}{ Design Project Realization } & $\begin{array}{c}\text { Project } \\
\text { Completion }\end{array}$ \\
\hline Stages & & \multicolumn{2}{|c|}{ Discovery } & \multicolumn{4}{|c|}{ Design Embodiment } & \multirow{2}{*}{$\begin{array}{l}\text { Project } \\
\text { Closeout }\end{array}$} \\
\hline Phases & & $\begin{array}{l}\text { Planning/ } \\
\text { Programming }\end{array}$ & $\begin{array}{c}\text { Conceptual } \\
\text { Design }\end{array}$ & $\begin{array}{c}\text { Schematic } \\
\text { Design }\end{array}$ & $\begin{array}{c}\text { Preliminary } \\
\text { Design }\end{array}$ & $\begin{array}{c}\text { Design } \\
\text { Development }\end{array}$ & $\begin{array}{c}\text { Construction } \\
\text { Documentation }\end{array}$ & \\
\hline Milestones & $\stackrel{\overrightarrow{n n t r a c t}}{\longrightarrow}$ & $\begin{array}{l}\text { Program/ } \\
\text { Start- }-\end{array}$ & $\begin{array}{l}\text { lirements } \\
\text { eeting }\end{array}$ & & & & & $\overrightarrow{\text { lover }}$ \\
\hline
\end{tabular}

Figure 4. First level company process model.

Within Figure 5 we have outlined the design steps of Figure 3 with practical model steps of the generic design phase (similar process in whole design embodiment phases). Similarly to the theoretical model, the steps can be categorized into two: design/analysis/invention and synthesis/making/delivery, as shown in Figure 3. Within each stage and phase, the 'outer' environment (customer voice) is translated into 'inner environment' and back to 'outer' environment for validation either through design briefing sessions or evaluation meetings. This concept of translation between the two (inner and outer) helps a designer working on the inner functioning and structuring of the system while also involving users and customer into the active dialogic of pros and cons of designs. Within this process, designers and engineers collectively or individually carry out reasoning and types of activities as proposed in proto-theory of design and design rhetoric.

Inside design phases, we have described the weekly or bi-weekly Plan-Do-Check-Act (PDCA) cycles and daily cycles (indicated with light blue and transparent orange in 
Figure 5). It is a generalization of the repetitive weekly PDCA cycle, describing the planning meetings with client and team, work execution and control, and the coordination (synthesis) of work-in-progress through model coordination and resolution, feeding back to team planning sessions. During the progression of a specific stage or weekly cycle, work-in-process results will be shared with clients as well, to get early feedback on design solutions.

After the process model development, it was introduced to the whole organization by respective participants from the model development meeting; i.e. the head of the structural engineering introduced to structural engineering department, the head of architecture to architectural department etc. The proposed model became the basis for developing further improvements, including but not limited to: checklists, meeting templates and structures, new classification system for design activities, BIM execution plan etc. Finally, a process for implementing a process was developed too. Every Wednesday, the CEO of the company checks with all projects managers and heads of the departments, if things outlined in process model are followed or not.

After several weeks, semi-structured interviews with persons who participated in the new design model development were conducted. Despite it being the first cycle of design science research, the main conclusion was that the development of the model and its introduction to people in company has helped to clarify the overall process. The new process model with new methodologies, methods and tools have significantly changed the way of working in the company. The next design science research cycle is planned for July 2017.

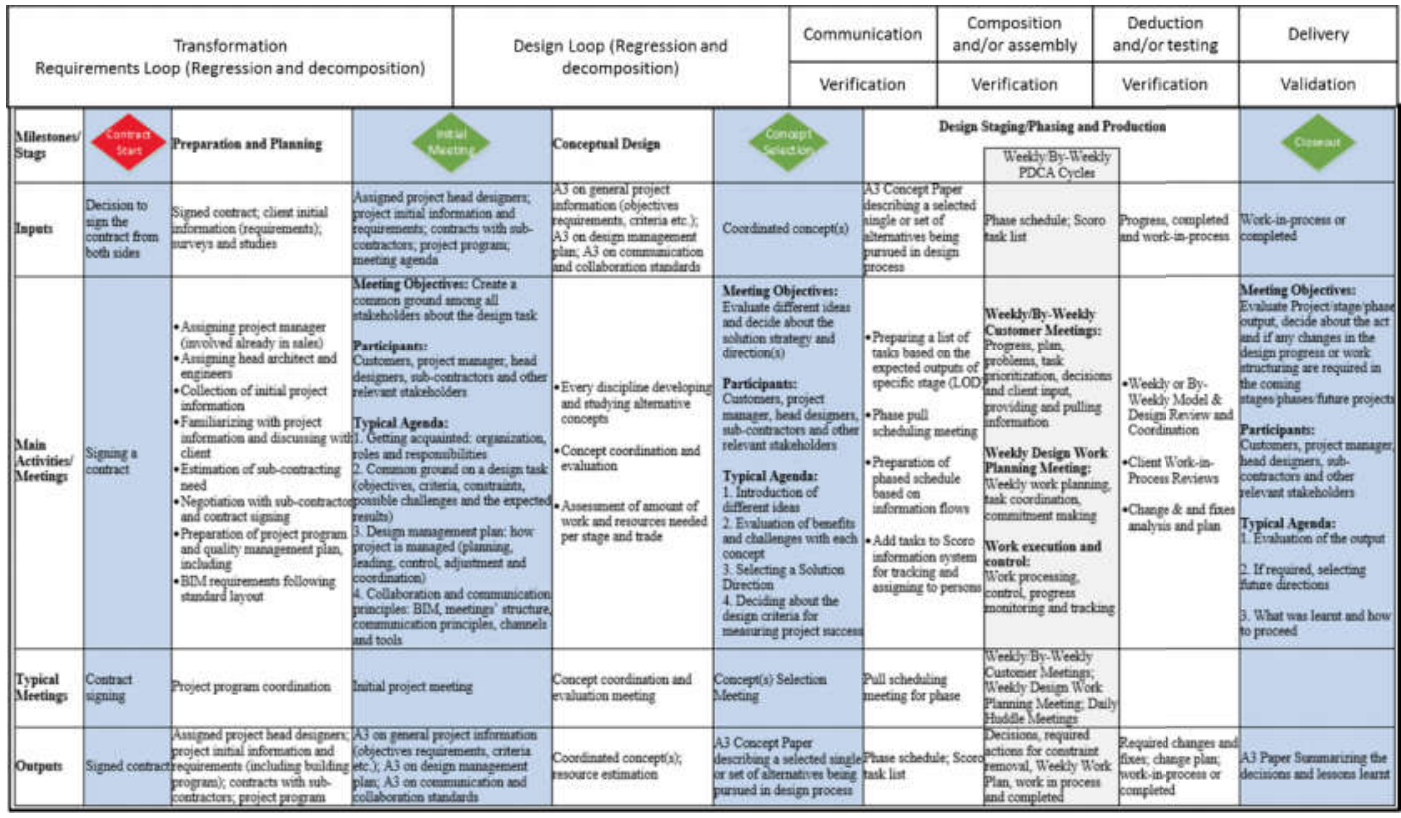

Figure 5. Comparison of the theoretical design process steps on top and practical model steps below.

\section{Conclusions}

Studying and developing a specific method or process model with the aid of a theory (proto-theory of design and rhetoric) is common in design research. In the given context it has allowed us to investigate the current situation and to devise a new theoretical and 
practical process and design management model for the case study design company. However as design is a premediated creative act, it sets extra challenges for design management, which need to be taken into account. Despite it being the first cycle of design science research, the main conclusion was that the development of the model and its introduction to people in company helped to clarify the overall process. Also, this model has been a catalyst for developing further improvements, including but not limited to: checklists, meeting templates and structures, new classification system for design activities, BIM execution plan etc.

\section{REFERENCES}

Ahmed, S., K. M. Wallace and L. T. Blessing (2003). "Understanding the differences between how novice and experienced designers approach design tasks." Research in Engineering Design 14(1): 1-11.

Andreasen, M. M., C. T. Hansen and P. Cash (2015). Conceptual Design: Interpretations, Mindset and Models, Springer.

Ballard, G. (2000). Lean Project Delivery System. White Paper-8 (Revision 1). Lean Construction Institute.

Buchanan, R. (2007). Strategies of Design Research: Productive Science and Rhetorical Inquiry. Design Research Now. R. Michel, Birkhäuser Basel: 55-66.

Eastman, C., P. Teicholz, R. Sacks and K. Liston (2011). BIM handbook: a guide to building information modeling for owners, managers, designers, engineers, and contractors, Wiley.

Fujimoto, T. (2007). "Architecture-based comparative advantage-a design information view of manufacturing." Evolutionary and Institutional Economics Review 4(1): 55112.

Hamzeh, F. R., G. Ballard and I. D. Tommelein (2009). Is the Last Planner System applicable to design? - A case study. Proc., 17th Annual Conf. of the Int. Group for Lean Construction (IGLC-17).

Hevner, A. R. (2007). "A three cycle view of design science research." Scandinavian journal of information systems 19(2): 4.

Huovila, P., L. Koskela, M. Lautanala, K. Pietiläinen and V. Tanhuanpää (1997). "Use of the design structure matrix in construction." Lean Construction: 417-425.

Kapurch, S. J. (2010). NASA Systems Engineering Handbook, DIANE Publishing.

Koskela, L., G. Howell, E. Pikas and B. Dave (2014). If CPM is so bad, why have we been using it so long? 22nd Annual Conference of the International Group for Lean Construction, Oslo L. K. B. T. Kalsaas, T. Abreu Saurin. Norway, 25. - 27. July 2014, Akademika forlag. 2014: 27 - 37.

Kroll, E. and L. Koskela (2015). "Applying the proto-theory of design to explain and modify the parameter analysis method of conceptual design." International Journal of Design Creativity and Innovation: 1-25.

Simon, H. A. (1981). "The sciences of the Artificial. First edition 1969." Massachusetts Institute of Technology: pp 215.

Sinclair, D. (2013). RIBA plan of work 2013 overview, London: Royal Institute of British Architects.

Wynn, D. C. (2007). Model-based approaches to support process improvement in complex product development, University of Cambridge. 